\title{
The influence of constrained fossil fuel emissions scenarios on climate and water resource projections
}

\author{
J. D. Ward ${ }^{1}$, A. D. Werner ${ }^{2,3}$, W. P. Nel ${ }^{4}$, and S. Beecham ${ }^{1}$ \\ ${ }^{1}$ Centre for Water Management and Reuse, School of Natural \& Built Environments, University of South Australia, \\ Mawson Lakes SA 5095, Australia \\ ${ }^{2}$ National Centre for Groundwater Research \& Training, Flinders University, G.P.O. Box 2100, Adelaide SA 5001, Australia \\ ${ }^{3}$ School of the Environment, Flinders University, G.P.O. Box 2100, Adelaide SA 5001, Australia \\ ${ }^{4}$ Sustainable Concepts, P.O. Box 4297, Cresta, Johannesburg, 2118, South Africa
}

Received: 4 February 2011 - Published in Hydrol. Earth Syst. Sci. Discuss.: 8 March 2011

Revised: 16 June 2011 - Accepted: 16 June 2011 - Published: 21 June 2011

\begin{abstract}
Water resources planning requires long-term projections of the impact of climate change on freshwater resources. In addition to intrinsic uncertainty associated with the natural climate, projections of climate change are subject to the combined uncertainties associated with selection of emissions scenarios, GCM ensembles and downscaling techniques. In particular, unknown future greenhouse gas emissions contribute substantially to the overall uncertainty. We contend that a reduction in uncertainty is possible by refining emissions scenarios. We present a comprehensive review of the growing body of literature that challenges the assumptions underlying the high-growth emissions scenarios (widely used in climate change impact studies), and instead points to a peak and decline in fossil fuel production occurring in the 21st century. We find that the IPCC's new RCP 4.5 scenario (low-medium emissions), as well as the B1 and A1T (low emissions) marker scenarios from the IPCC's Special Report on Emissions Scenarios are broadly consistent with the majority of recent fossil fuel production forecasts, whereas the medium to high emissions scenarios generally depend upon unrealistic assumptions of future fossil fuel production. We use a simple case study of projected climate change in 2070 for the Scott Creek catchment in South Australia to demonstrate that even with the current suite of climate models, by limiting projections to the B1 scenario, both the median change and the spread of model results are reduced relative to equivalent projections under an unrealistic high emissions scenario (A1FI).
\end{abstract}

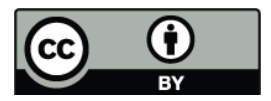

Correspondence to: J. D. Ward (james.ward@unisa.edu.au)

\section{Introduction}

It is widely anticipated that anthropogenic climate change will have significant impacts on freshwater resources worldwide (Kundzewicz et al., 2007). Large-scale water resources infrastructure such as dams, pipelines and desalination plants are typically designed for service lives of $50 \mathrm{yr}$ or more. With such long planning horizons, it is particularly important within the water industry to understand the uncertainty surrounding long-term projected impacts of climate change and to find ways to minimize this uncertainty.

Sivakumar and Sharma (2009) summarized the scientific challenges that we face in the sustainable management of our future water resources. These challenges include identification of the actual causes of climate change, development of General Circulation Models (GCMs) that can adequately incorporate these causes to generate dependable future climate projections at larger scales, formulation of appropriate techniques to "transform" (i.e. downscale) the GCM outputs to regional and local conditions for hydrological analysis and projections, and reliable estimation of the associated uncertainties in all these steps.

There is currently a somewhat controversial landscape with respect to the perceived relevance or irrelevance of GCMs to hydrological studies. The debate is largely centered around the question of whether GCMs are capable of reproducing realistic climate characteristics (Koutsoyiannis et al., 2009b; Kundzewicz et al., 2009). Anagnostopoulos et al. (2010) compared the outputs of several GCMs with observed temperature and precipitation data, concluding that, even on large spatial and temporal scales, the models do a poor job of representing the observed climate. Moreover, they concluded that a deterministic approach to climate modeling was insufficient, and that future projections

Published by Copernicus Publications on behalf of the European Geosciences Union. 
must consider the intrinsic or "structural" uncertainty of hydrology (and climate in general), which may be more appropriately represented by a stochastic approach. The point of structural uncertainty was also made by Koutsoyiannis (2010), who demonstrated that even a simple deterministic "toy" climate model without external forcings can produce chaotic and uncertain results, fluctuations, and trends similar to those observed in the real world climate. Koutsoyiannis (2010) proposed that a stochastic approach using a deterministic dynamic model within a Monte Carlo framework (to account for inherent lack of precision and accuracy in values such as initial conditions) can be considered an "all-times solution", providing a useful explanation of uncertainty over short and long timeframes. Meanwhile, a deterministic dynamic model that is not implemented within a stochastic (e.g. Monte Carlo) framework will give "misleading results and a dangerous illusion of exactness" over long timeframes. Even with the very slightest uncertainty (e.g. in the order of $10^{-6}$ ) in initial conditions, the toy model of Koutsoyiannis (2010) showed complete divergence in the stochastic simulation over the long timeframe. This finding has been used to suggest implicitly that the GCM-based attribution of observed climatic trends (e.g. rising temperatures and changes in rainfall) to greenhouse gas emissions may be overstated (Christofides and Koutsoyiannis, 2011). This questions the usefulness of GCMs for projections under future greenhouse gas emissions. In related articles, Wilby (2010) and Kundzewicz and Stakhiv (2010) both recognised the original intent of GCMs, namely to assess the global climatological implications of different emissions pathways, in contrast to the more recent tendency to use such models to drive regional or local hydrological impact assessments. Wilby (2010) concluded that "characterising" uncertainty in climate projections may be more achievable than "reducing" uncertainty.

While we recognise that there are significant and interesting ongoing issues relating to intrinsic uncertainty in the climate system, and the appropriateness or otherwise of using GCMs for attribution studies and/or impact projections, research continues to emerge that depends heavily on the assumption that GCMs and their projections are reliable. This includes the study by Kirono et al. (2011), who looked at droughts in Australia under several modeled climate change scenarios. In such studies, the current wide range of "plausible" greenhouse gas emissions scenarios presents a significant extra source of predictive uncertainty (in addition to the intrinsic uncertainty) in future climate, in the form of divergent model results. In the following discussion we will show that there is significant scope to reduce this predictive uncertainty through refining the emissions scenarios.

The main stages in developing a model of the hydrological impacts from climate change are shown in Fig. 1. When attempting to make a future projection, as opposed to a hypothetical scenario or numerical experiment, the uncertainty begins with the need to arbitrarily choose a greenhouse gas

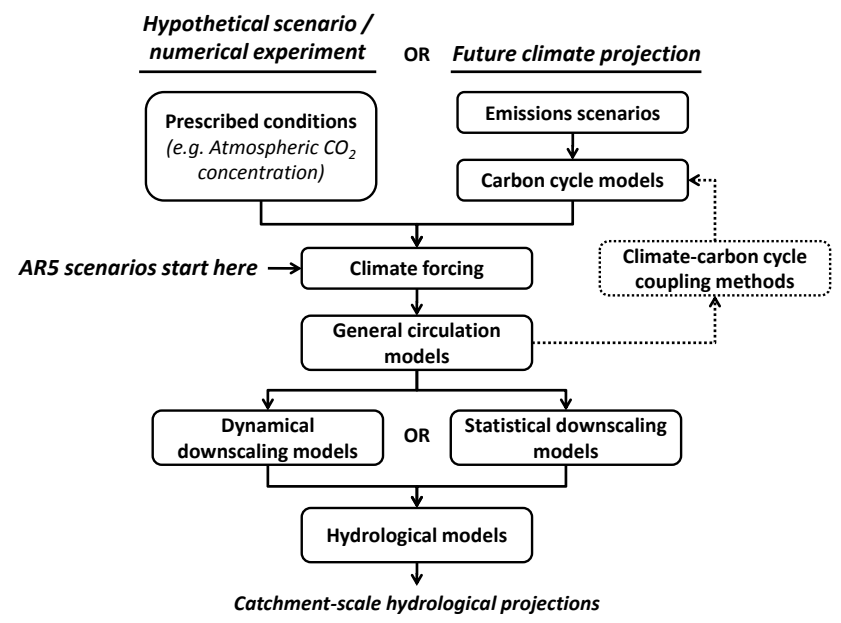

Fig. 1. Simplified chart of the main processes involved in modeling hydrological impacts from climate change. Note: Dashed lines around climate-carbon cycle coupling methods indicate that not all models are coupled.

emissions scenario, and this initial uncertainty is then compounded by further modelling variability all the way to the final catchment-scale projection. The uncertainty introduced at each step comes from the need to choose from a (sometimes diverse) range of models, plus variability in the observational data used to parameterise each model.

Given the compounding nature of these uncertainties in modeled climate projections, it is important to understand where (or when) particular factors are dominant. Hawkins and Sutton (2009) gave a useful assessment of the three main sources of uncertainty in current projections for global temperature change and related this to the timescale of the projection. The sources of uncertainty they considered were:

1. internal variability (natural climatic variability and short-term changes that can cause temporary departures from longer-term trends);

2. model uncertainty (differences in numerical schemes, modelling assumptions, coupling processes, parameterization, etc.); and

3. scenario uncertainty (differences in projected greenhouse gas (GHG) emissions and the resultant climate forcing).

They showed that in the short to medium term (several decades), model uncertainty dominates the overall uncertainty in temperature projections. However, according to Hawkins and Sutton (2009), the relative influence of scenario uncertainty grows rapidly over time and by 2100 , scenario uncertainty dominates overall uncertainty (almost four times more than the model uncertainty). For long-term projections of global temperature change, internal variability was shown to be negligible. 
A similar analysis of uncertainty in future precipitation changes was undertaken by Hawkins and Sutton (2011), who found that, unlike temperature, a combination of modeling uncertainty and internal variability heavily dominates projected global and regional changes in precipitation up to 2100. This supports earlier research by Covey et al. (2003) and Arnell (2003) who found that the variability in long-term hydrological predictions were dominated by modeling differences rather than by emissions trajectories. In short, the current GCMs are unable to produce a consistent projection of long-term precipitation changes either regionally or globally. This is in part due to the fact that precipitation, unlike temperature, is a secondary variable or output from GCMs. This is unfortunate because while it might be a secondary output from a GCM, precipitation is a primary input to hydrological models. Despite this significant issue, emissions scenario uncertainty remains an important source of uncertainty in hydrological projections, for three reasons:

1. temperature change (for which models are in broad agreement over the long-term, and for which emissions scenario choice is important) is hydrologically significant, both directly due to its role in evaporation (Morton, 1983), and indirectly via its interaction with the global carbon cycle (Friedlingstein et al., 2006);

2. plant growth is highly dependent on temperature and atmospheric $\mathrm{CO}_{2}$ (both of which substantially depend on the emissions scenario), and modeled vegetation processes have been shown to contribute significantly to the hydrological cycle, especially runoff (Betts et al., 2007); and

3. future advances in modeling techniques and improved understanding of the relative performance of individual models (Knutti, 2010; Smith and Chandler, 2010) are expected to reduce model uncertainty in precipitation projections, thereby placing a greater emphasis on emissions scenarios.

There is an emerging, but steadily growing body of research (Brecha, 2008; Höök et al., 2010a, b; Nel and Cooper, 2009; Murray, 2009; Ward and Nel, 2010; Rutledge, 2011) that constrains future fossil fuel projections to the lower end of the range currently being considered in climate change studies. In this paper it is argued that these limits to future fossil fuel consumption should be considered in the selection of emissions scenarios. The primary objective of the current paper is to explore the likely implications of limits to fossil fuel production (and the subsequent constraint on $\mathrm{CO}_{2}$ emissions) on predictive uncertainty, within the broader context of the importance of emissions scenarios for freshwater resource projections. The recent advances in fossil fuel research may assist in reducing uncertainty for long-term projections of climate change impacts, which would be significant for water resource planners.
A brief history of climate scenarios is presented, as well as a review of the growing body of literature on fossil fuel constraints that challenge the GHG emissions assumptions underlying the majority of emissions scenarios currently in use in impact studies. A case study is then used to demonstrate that even with the current suite of models, a substantial reduction in overall prediction uncertainty may be achieved by implementing realistic fossil fuel forecasts.

The scope of the current paper is primarily to investigate the opportunity to constrain emissions scenarios using published fossil fuel production estimates, and to study the possible influence this may have on hydrological predictions. However, in the case of rainfall, an argument could be made that we are unable to discern much at all from GCMs regarding climate change impacts, and that natural fluctuations will continue to dominate the long-term pattern. This may be highly relevant under low emissions scenarios, where we will show that the severity and the uncertainty surrounding the predicted change are both reduced, relative to high emissions scenarios.

\section{Climate scenarios used in water resource projections}

Climate scenarios have been evolving since the earliest numerical modeling in the 1960s and Moss et al. (2010) provide a useful timeline of their development. Climate scenarios can be broadly grouped into two categories. The first category (the right-hand side of Fig. 1) involves a series of what the IPCC considers to be "plausible" projections of future climate based on GHG emissions, which are usually accompanied by projections of global and regional population and economic growth (among other variables). These types of projections have been prominent in many recent impact studies and have included the IS92 series (Leggett et al., 1992), later replaced by the Intergovernmental Panel on Climate Change (IPCC) Special Report on Emissions Scenarios, or SRES (Nakicenovic and Swart, 2000). The SRES scenarios contained 40 "storylines" describing global and regional population growth, economic growth and technology change, and gave the resulting GHG emissions in each case. The 40 scenarios are divided into four "families" (A1, A2, B1, B2) describing core assumptions of future regional and global population growth, economic development, energy use and other factors. To simplify comparison studies, each family is given a representative "marker" scenario. In addition to the four marker scenarios, two extra marker scenarios from the A1 family are included by Nakicenovic and Swart (2000). These are the A1G MINICAM (more commonly known as A1FI), which denotes a fossil fuel intensive trajectory, and A1T, which denotes a predominantly non-fossil fuel trajectory. The cumulative emissions under each marker scenario are summarized in Table 1. The name of each marker scenario (AIM, MESSAGE, etc.) refers to the modeling group responsible for converting the qualitative 
storyline into a quantitative greenhouse gas emissions pathway. Nakicenovic and Swart (2000) explicitly state that all scenarios have equal likelihood, and Manning et al. (2010) observe that cumulative global GHG emissions (and resultant atmospheric $\mathrm{CO}_{2}$ concentrations) from 1990-2008 were approximately in the middle of the range of the six marker scenarios.

The second category of future climate projections involves purely "academic" scenarios (the left-hand side of Fig. 1). These do not claim to project plausible futures, but instead investigate the impact of some hypothetical perturbed climate relative to a control experiment. For example, this could compare the difference between two simulated climates where one undergoes a $1 \%$ p.a. steady increase in atmospheric $\mathrm{CO}_{2}$ and the other has static $\mathrm{CO}_{2}$ concentrations (Covey et al., 2003), or it could compare the difference in simulated climates between a pre-industrial situation and a "doubled- $\mathrm{CO}_{2}$ " scenario (Allen et al., 2003).

Given the dominance of model uncertainty in long-term precipitation uncertainty (Hawkins and Sutton, 2011) in most studies of projected climate change impacts on water resources, the influence of the emissions scenario (or scenario uncertainty) is not the focus of the investigation. Rather, these studies tend to focus on novel climatic or hydrological modeling techniques and the associated assumptions and uncertainties. For instance, Douville et al. (2002) presented the results of a global rainfall and runoff model considering two scenarios: constant 1950s GHG emissions (control case) versus the SRES B2 marker scenario with $\mathrm{CO}_{2}$ rising to $620 \mathrm{ppm}$ by the end of the $21 \mathrm{st}$ century. With only one future emissions trajectory being tested, such a study could not quantify the influence of different possible emissions pathways. Similarly, Döll (2002) presented the results of a model for global irrigation demand, based on the outputs of two GCMs and one emissions scenario (IS92a). Booij (2005) modelled the Meuse River basin discharge under current and changed climates, considering a "current" climate (1970-1999) and an academic scenario of a hypothetical doubled- $\mathrm{CO}_{2}$ climate. Betts et al. (2007) investigated global runoff changes under a simulated pre-industrial climate versus a doubled- $\mathrm{CO}_{2}$ climate. Downing et al. (2003) considered multiple emissions scenarios covering a wider range of possible long-term futures. However the focus of the project was limited to the 2020 s, which proved too short a timeframe for the various emissions scenarios to significantly diverge.

CSIRO (2007) analysed the results of 23 GCMs extending to the 2070s and for each model evaluated changes in annual and seasonal temperature, precipitation, wind speed, solar radiation and potential evaporation across the Australian continent, relative to a baseline period of 1980-1999. They considered three marker scenarios from SRES - low (B1), medium (A1) and high (A1FI) - and presented the results visually as 10th, 50th and 90th percentiles to demonstrate the spread of model results across each scenario. The graphical results are
Table 1. Cumulative projected emissions under six SRES marker scenarios (after Nakicenovic and Swart, 2000).

\begin{tabular}{lrr}
\hline \multirow{2}{*}{ Marker Scenario } & \multicolumn{2}{c}{ Cumulative emissions (GtC) } \\
\cline { 2 - 3 } & $1990-2050$ & $1990-2100$ \\
\hline A1 AIM & 730.6 & 1492.1 \\
A2 ASF & 728.6 & 1855.3 \\
A1G MINICAM (A1FI) & 820.9 & 2182.3 \\
B2 MESSAGE & 554.5 & 1156.7 \\
A1T MESSAGE & 623.1 & 1061.3 \\
B1 IMAGE & 599 & 975.9 \\
\hline
\end{tabular}

available online (http://www.climatechangeinaustralia.com. au/futureclimate.php, accessed on 11 January 2011). For changes to rainfall in the long-term (2070s), the most obvious source of uncertainty is from model differences. However, both the median change and the spread of model results depend (albeit slightly) on the choice of emissions scenario. As expected, the results of CSIRO (2007) for long-term change in temperature and potential evaporation show a more obvious dependence on emissions scenario than was observed for rainfall, with a substantial increase in both the median and the model spread under high emissions, relative to the low emissions scenario. We revisit the results of CSIRO (2007) in our case study below.

A recent advance in the development of emissions scenarios was reported by Moss et al. (2010), with a new suite of scenarios to replace SRES in the IPCC's forthcoming Fifth Assessment Report (AR5), and in future climate change impact studies. The new range consists of four projections of radiative climate forcing, which are independent of socio-economic or GHG emissions projections (see Fig. 1). For those interested in making climate change projections based on plausible future GHG emissions trajectories, Moss et al. (2010) have proposed a "representative concentration pathway" (RCP) for each scenario, taking specific emissions pathways that could plausibly lead to each of the four radiative forcing pathways, although they are careful to explain that there are multiple possible emissions scenarios that could lead to the same ultimate radiative forcing outcome. The four RCP scenarios are summarized in Table 2 in terms of cumulative emissions over the 21 st century, longterm concentrations of atmospheric $\mathrm{CO}_{2}$ (equivalent) and the resultant radiative forcing.

One significant issue with all emissions scenarios is that the global carbon cycle and associated climate feedbacks remain a major source of uncertainty in the relationship between GHG emissions pathways and the ultimate radiative forcing (Moss et al., 2010; Friedlingstein et al., 2006; Jones et al., 2006). For instance, GCMs which can couple climate change to the carbon cycle are yet to converge on a consistent result for $\mathrm{CO}_{2}$ feedback, which presently varies 
from $20 \mathrm{ppm}$ to $200 \mathrm{ppm}$ over a $100 \mathrm{yr}$ simulation for a single emissions scenario, depending on the model (Friedlingstein et al., 2006). In this paper, we follow the convention that low emissions pathways correspond broadly to low radiative forcing pathways, and high emissions pathways correspond broadly to high radiative forcing pathways.

For each emissions scenario, it must be assumed either implicitly or explicitly that there is sufficient fossil fuel remaining to be produced and burnt, and that this fuel can be extracted at a sufficient rate that produces the projected rise in atmospheric $\mathrm{CO}_{2}$ (see Nakicenovic and Swart, 2000). The factors controlling most of the hypothetical emissions pathways are economic, social and political (e.g. the future rate of population growth, rising affluence in developing countries and the potential national or global adoption of GHG emissions reduction policies), while the concept of physical constraints to actual future fossil fuel production has been dismissed (Höök et al., 2010a).

\section{Fossil fuel resources as a constraint to emissions scenarios}

The formal assessment of risk considers not only the consequence of a hazard (e.g. the severity of a particular "climate change impact"), but also the likelihood of that hazard occurring. Jones (2001) advocated an approach to climate change risk assessment wherein the whole analysis is conducted within an assumed future emissions pathway (e.g. assessing the likelihood of a $50 \%$ reduction in catchment streamflow under the A1FI scenario). We contend that a more complete risk assessment - if at all possible - would in fact sit above the emission pathways, and should include an assessment of the likelihood of each scenario occurring, followed by the specific impacts of interest under each scenario. Within such a framework, the probability of an impact occurring under a given emissions scenario would be multiplied by the probability of that emissions scenario occurring. To do this quantitatively requires substantial numerical effort, and we intend to address this in subsequent research. However, in the present paper, we take a qualitative approach to simply show that the low emissions scenarios now appear far more likely to occur than the high emissions scenarios. In turn, any impacts that have been simulated assuming high emissions must be considered relatively unlikely compared with impacts simulated assuming low emissions. These ideas should be considered by policy-makers in their conceptualisation of risk under climate change.

The limits to the Earth's fossil fuel resources have been widely discussed for more than half a century. These discussions have been influenced by Hubbert $(1949,1956)$, as well as the Club of Rome (Meadows et al., 1972), and a series of lectures and articles by Bartlett (1978, 1981, 1994, 2000), among others (e.g. Laherrere, 2001; Bentley, 2002). As in climate modeling, improvements to computer technol- ogy and modeling techniques have led to increasingly sophisticated estimates for fossil fuel reserves and predictions for future production rates, and these predictions are gradually converging. The most well-known predictions are for future oil production (e.g. Mohr and Evans, 2008; Aleklett et al., 2010). Sorrell et al. (2010a, b) report the results of an exhaustive review of some 500 separate oil production studies, concluding that oil production is likely to decline before 2030. Perhaps less well-known are the recent predictions of coal supply, pointing to a possible pre-2050 peak in global coal production (e.g. Mohr and Evans, 2009; Höök et al., 2010b; Lloyd and Subbarao, 2009; Lin and Liu, 2010; Patzek and Croft, 2010). Mohr (2010) presents a combined estimate for world oil, coal and natural gas production. The consensus emerging in the literature is that fossil fuel production is nearing a peak and will decline sometime in the 21 st century, as the larger, mature resources reach the end of their productive life and are replaced with either smaller resources, or resources that are slower to extract.

Despite the long-term discussion of fossil fuel resource limits, many projections of future anthropogenic climate change have assumed that continuous growth in GHG emissions will be possible for several centuries (i.e. long enough to trigger significant climate change). Höök et al. (2010a) reviewed the development of the IPCC's emissions scenarios, mostly referring to Nakicenovic and Swart (2000), and contrasted these scenarios against the growing body of literature regarding fossil fuel depletion. They criticized the "unnecessarily optimistic" assumptions of continual growth in fossil fuel production by the IPCC.

Only recent research has reconciled fossil fuel limits and emissions scenarios. Laherrere (2001) was among the first to explicitly challenge the IPCC's assumption that continual growth in fossil fuel production would be possible, claiming instead that global oil and gas production would barely keep up with the lowest of the SRES scenarios through the 21 st century. Doose (2004) discussed fossil fuel limits, GHG emissions and climate change, and based on a simplistic carbon sink model and a basic fossil fuel production model, concluded that future atmospheric $\mathrm{CO}_{2}$ concentrations may not rise any higher than $650 \mathrm{ppm}$. There have been similar studies by Kharecha and Hansen (2008) who investigated a range of hypothetical future fossil fuel scenarios with declining oil production with a simple carbon sink model, and found that $\mathrm{CO}_{2}$ concentrations could be limited to around $450 \mathrm{ppm}$, but this would depend on not exploiting excess coal or unconventional fossil fuels. Brecha (2008) presented a similar analysis, concluding that the maximum $\mathrm{CO}_{2}$ concentration under a "high emissions" scenario, but constrained by resource limits, may be approximately $560 \mathrm{ppm}$, peaking around the year 2075.

$\mathrm{Nel}$ and Cooper (2009) presented several possible fossil fuel production trajectories and challenged the strength of climate-carbon cycle feedbacks as assumed in the BERN carbon cycle model (Siegenthaler and Joos, 1992). Nel 
Table 2. RCP scenarios (from Moss et al., 2010).

\begin{tabular}{|c|c|c|c|}
\hline Scenario & Radiative forcing & $\begin{array}{l}\text { Atmospheric concentration } \\
(\mathrm{ppm})\end{array}$ & $\begin{array}{r}\text { Approx. } \\
\text { cumulative } \\
\text { emissions } \\
\text { (GtC) } 2000-2100\end{array}$ \\
\hline RCP 2.6 & $\begin{array}{l}\sim 3 \mathrm{~W} \mathrm{~m}^{-2} \text { before } 2100, \\
\text { then declines }\end{array}$ & $\begin{array}{l}\text { Peak at } \sim 490 \mathrm{CO}_{2} \text { equiv. } \\
\text { before } 2100 \text { then declines }\end{array}$ & 370 \\
\hline $\mathrm{RCP} 4.5$ & $\begin{array}{l}\sim 4.5 \mathrm{~W} \mathrm{~m}^{-2} \text { at } \\
\text { stabilization after } 2100\end{array}$ & $\begin{array}{l}\sim 650 \mathrm{CO}_{2} \text { equiv. } \\
\text { at stabilization after } 2100\end{array}$ & 830 \\
\hline $\mathrm{RCP} 6.0$ & $\begin{array}{l}\sim 6 \mathrm{~W} \mathrm{~m}^{-2} \text { at } \\
\text { stabilization after } 2100\end{array}$ & $\begin{array}{l}\sim 850 \mathrm{CO}_{2} \text { equiv. } \\
\text { at stabilization after } 2100\end{array}$ & 1260 \\
\hline RCP 8.5 & $>8.5 \mathrm{~W} \mathrm{~m}^{-2}$ in 2100 & $>1370 \mathrm{CO}_{2}$ equiv. in 2100 & 1960 \\
\hline
\end{tabular}

and Cooper (2009) showed that under their high fossil fuel reserves scenario, using a parameterized carbon feedback model calibrated to empirical evidence, atmospheric $\mathrm{CO}_{2}$ concentrations would peak at 440-480 ppm around the year 2070 , falling to $340-360 \mathrm{ppm}$ by 2200 . They also showed that under the BERN carbon cycle model (a process-based model without corrections for missing sinks), the same fossil fuel scenario would result in peak $\mathrm{CO}_{2}$ concentrations of $540 \mathrm{ppm}$ around the year 2100 , remaining above $500 \mathrm{ppm}$ through to 2200. The issue of positive versus negative carbon cycle feedback assumptions under low emissions trajectories was identified earlier by Kharecha and Hansen (2008), who made the point that under low emissions scenarios, a negative feedback (where carbon sinks remain effective) may result in a climate forcing that is much less than that under scenarios with continually rising emissions and positive carbon cycle feedbacks. Tans (2009) used oceanic and atmospheric observations of carbon to constrain an empirical carbon sink model, and concluded that the carbon cycle has become more effective over recent years in removing anthropogenic $\mathrm{CO}_{2}$ from the atmosphere. Using a simple logistic model of future fossil fuel production to 2500, Tans (2009) predicted atmospheric $\mathrm{CO}_{2}$ concentrations would peak at $500 \mathrm{ppm}$ in the year 2069 (for a conventional resources scenario) and $600 \mathrm{ppm}$ in the year 2090 (for a conventional + unconventional oil resources scenario). Tans (2009) extended his results to consider possible future radiative forcings, which were predicted to peak in the same years as atmospheric $\mathrm{CO}_{2}$ concentration, at $3 \mathrm{~W} \mathrm{~m}^{-2}$ (conventional) and $4 \mathrm{~W} \mathrm{~m}^{-2}$ (conventional + unconventional), broadly consistent with the RCP 2.6 and RCP 4.5 scenarios from Moss et al. (2010) (see Table 2).

Rutledge (2011) provided a detailed history of world coal production and presented a method for predicting ultimate production based on historical trends. He observed that in mature coal-producing regions, early coal reserve estimates have consistently been much higher than the ultimately recovered amount, yet downward revisions to reserve estimates typically occur quite late in the production history. Rutledge (2011) also discussed the important differences between "reserves" (coal that can be produced economically with current technology) versus "resources" (coal that could potentially be produced in the future), and the tendency for large amounts of coal to move between these classifications due to periodic changes in estimation techniques or policies. Importantly, Rutledge (2011) pointed out that there is a further category (called "additional recoverable reserves") that has proven very unreliable in historical surveys. However the SRES predictions for high future coal production (Nakicenovic and Swart, 2000) are dependent on a single, apparently anomalous estimate of additional recoverable reserves by the World Energy Council (WEC, 1998). The WEC subsequently downwardly revised its estimates, and by 2007 was stating global coal reserves totaling less than one quarter of their 1998 estimated value (WEC, 2007). While Rutledge (2011) predicted only ultimate coal production, a prediction for future coal production rates was presented by Patzek and Croft (2010) via a multi-Hubbert cycle analysis for different producing regions, concluding that global coal production (and associated GHG emissions) could peak as early as 2011 , and decline to half of the peak production rate by 2047. This result may be overly pessimistic, and the limitations of the multi-Hubbert cycle approach were discussed by Anderson and Conder (2011). Most notably, this approach can allow overly complex curves to be produced that provide an excellent match to the historical data but lack a physical basis and therefore do not aid in future predictions. However, independent forecasts by Mohr and Evans (2009) and Höök et al. (2010b) using different methods also suggest that world coal production will probably reach a peak before 2050, falling well short of the IPCC's high emissions scenarios.

With the mounting arguments for fossil fuel limits, there is now an opportunity to refine the emissions scenarios adopted in climate change impact studies. Figure 2 shows a comparison between fossil fuel GHG emissions (solid lines) 


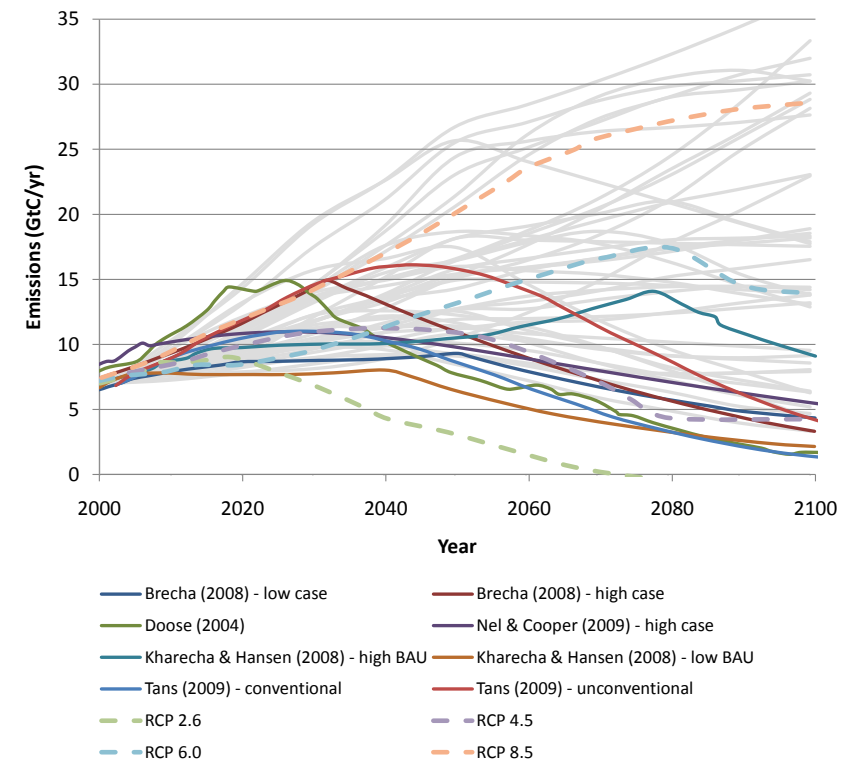

Fig. 2. Comparison between various published projections for emissions due to fossil fuel production against the RCP scenarios from Moss et al. (2010). The faint grey lines correspond to the 40 SRES scenarios presented in Nakicenovic and Swart (2000).

from the studies reviewed above, versus the new RCP scenarios (dashed lines) from Moss et al. (2010). For brevity, we have included only those projections where a $\mathrm{CO}_{2}$ emissions trajectory was included in the published study; many other studies of future fossil fuel production focus on energy but do not convert produced fuel into emissions. The 40 SRES scenarios are included (faint grey lines) in the background of the plot, for reference. It should be noted that current fossil fuel emissions are approximately $8.5 \mathrm{GtC} \mathrm{yr}^{-1}$ (Myhre et al., 2009; Manning et al., 2010), which is roughly in the middle of the range of projections.

From Fig. 2, it can be seen that most of the SRES scenarios are significantly over-predicting emissions from around 2030 onwards with respect to the more recent studies of future fossil fuel production. The low-medium RCP 4.5 scenario offers the best visual match to the recent studies. The low scenario RCP 2.6 appears to be slightly too low, while the high scenario RCP 8.5 (similar to the upper SRES scenarios) corresponds to unrealistic fossil fuel production. The RCP 6.0 scenario (medium-high) is also unrealistic with respect to most scenarios, the exceptions being Kharecha and Hansen's (2008) high business-as-usual (BAU) scenario and the unconventional fossil fuel scenario from Tans (2009). Kharecha and Hansen's (2008) high BAU scenario is hypothetical in nature, assuming a steady $2 \%$ p.a. growth in global production of each fossil fuel (coal, oil and gas) until half of the global reserve remains, at which point production switches to a decline of $2 \%$ p.a. This does not represent a sophisticated attempt to predict actual future fossil fuel production. It should be noted that Brecha's (2008) scenarios are, like

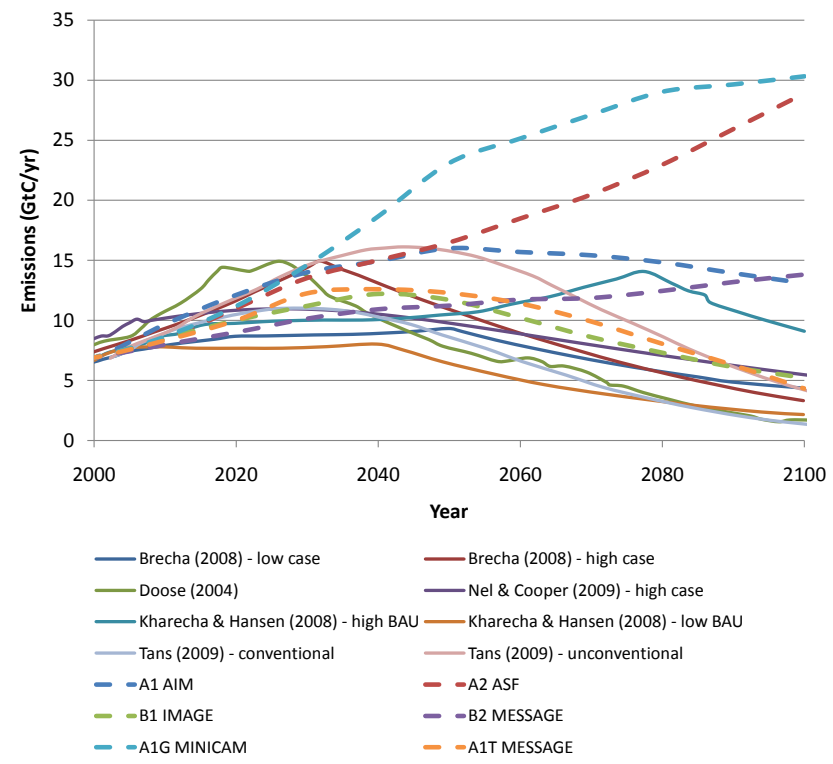

Fig. 3. Comparison between various projections for GHG emissions due to fossil fuel production and the six SRES marker scenarios presented in Nakicenovic and Swart (2000).

Kharecha and Hansen's high BAU scenario, similarly hypothetical in nature. The high scenario of Tans (2009) was simplistic, and involved the optimistic assumption of a seamless adoption of unconventional fossil fuels (shale oil, bitumen and heavy oil) to sustain a 2 to $3 \%$ annual growth in total fossil fuel production over the next few decades. Mohr and Evans (2010) provided a more sophisticated modeling approach for unconventional oil, and concluded in their "best guess" scenario that total oil production (conventional + unconventional) would begin declining within $5 \mathrm{yr}$.

Because the RCP scenarios (Moss et al., 2010) have yet to be widely implemented in climate change impact studies, it is relevant to also compare the performance of SRES scenarios (on which the majority of studies have been based) against fossil fuel production studies. Figure 3 shows the same fossil fuel studies presented in Fig. 2, but this time we compare them against the six SRES marker scenarios (Nakicenovic and Swart, 2000). The closest agreement is found with the B1 and A1T marker scenarios. The A1G MINICAM (A1FI) and A2 marker scenarios do not correspond to realistic fossil fuel production trajectories. The A1 and B2 scenarios are somewhat similar to the RCP 6.0 scenario, and are higher than the majority of fossil fuel projections.

It is important to note that some models predict large changes in climate (relative to recent observations) even under low emissions scenarios. Allen et al. (2009) and Meinhausen et al. (2009) both present results of a simplified coupled climate-carbon cycle model that shows how even low emissions pathways may potentially lead to a global mean surface temperature (GMST) increase in excess of $2{ }^{\circ} \mathrm{C}$, with results depending on the assumptions of the models. There 


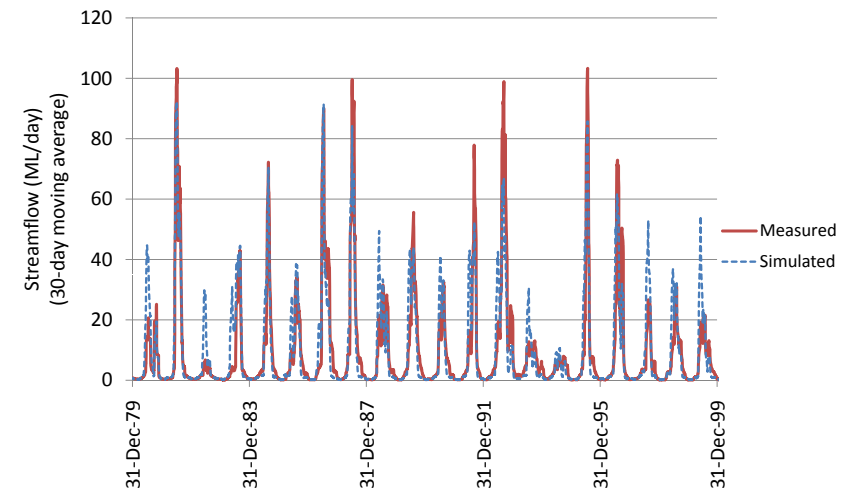

Fig. 4. Observed and simulated streamflows in the calibrated GWLF model.

are multiple (compounding) layers of model uncertainty associated with coupled climate-carbon cycle models, and until recently there has been a lack of observational data to constrain model parameters (Jones et al., 2006). However, recent observational evidence has been presented suggesting that climate-carbon cycle feedbacks may be at the lower end of the range previously being considered (Mahecha et al., 2010; Frank et al., 2010). If, in the future, more sophisticated coupled climate-carbon cycle models (constrained by more reliable observational data) converge on a particular level of feedback (low or high), then current climate change forecasts may need to be revised. The positive aspect of this (even if feedbacks turn out to be high) would be that overall model uncertainty would be reduced. Irrespective of whether ultimately agreed feedbacks are high or low, it will be even more important to consider the most realistic emissions scenarios available.

\section{Case study - Scott Creek catchment, South Australia}

A case study is presented here to demonstrate the influence of emissions scenario choice on projected climate change impacts, using a simple hydrological model and scenario framework. This case study is intentionally brief and full details of the study area, methodology and hydrological modelling are provided in Haith et al. (1992) and Banks et al. (2009).

\subsection{Site description}

The research catchment, Scott Creek, is a $28.5 \mathrm{~km}^{2}$ upland catchment in the Mt Lofty Ranges, South Australia (location: $35^{\circ} 05^{\prime} \mathrm{S}, 138^{\circ} 41^{\prime} \mathrm{E}$ ). The creek is approximately $10 \mathrm{~km}$ long with the lower $8.5 \mathrm{~km}$ flowing perennially. The catchment is an active hydrogeology research site (Harrington, 2004; James-Smith and Harrington, 2002; Kwantes, 2006; Werner et al., 2008; Banks et al., 2009). Interest in Scott Creek is further stimulated by the fact that the creek flows into the Onkaparinga River, upstream of a major water supply dam for the city of Adelaide. In addition, the stream has a substantial historical data record including $38 \mathrm{yr}$ of daily flow recording, and $34 \mathrm{yr}$ of salinity observations.

\subsection{Model description and calibration}

The model developed in this study is based on the Generalized Watershed Loading Function (GWLF) from Haith et al. (1992). GWLF uses linear assumptions and two subsurface compartments. Previous application of this model has demonstrated its success at modelling stream flow and non-point source pollutant loadings, such as nutrients and sediment loads (Lee et al., 2000; Lee et al., 2001; Schneiderman et al., 2002). This model uses the parsimonious Curve Number $(\mathrm{CN})$ approach to calculate surface runoff. The $\mathrm{CN}$ approach accounts for catchment soil type, land-use and antecedent moisture condition to predict the runoff fraction of a rainfall event (Mishra and Singh, 2003). The CN approach does not distinguish between infiltration and saturation excess runoff, shallow unsaturated sub-surface flow and direct channel precipitation (Garen and Moore, 2005); nor does it account for the baseflow portion of the hydrograph. Saturation excess runoff occurs when the soil can no longer store more water, in which case any rainfall immediately runs off. Infiltration excess runoff occurs when the rainfall intensity exceeds the infiltration capacity of the soil, and the rainfall that cannot be absorbed is converted to runoff. GWLF nonspecifically routes deeper sub-surface flow through shallow saturated zones to the stream. In this study, GWLF is combined with a salinity mixing model. The model is calibrated to an objective function that integrates stream salinity and stream flow hydrograph simulation error. Figure 4 compares observed and simulated streamflows for the calibrated model.

\subsection{Climate change scenarios}

CSIRO (2007) reviewed 23 GCMs and summarised the seasonal changes to key climatic variables in Australia (including rainfall, wind speed, temperature and potential evaporation) by 2030, 2050 and 2070. They expressed these changes as percentile values (10th, 50th and 90th) relating to the number of models exceeding each value. Hence they present a "best guess" (i.e. the median of the model results) as well as a measure of the spread across the model results.

For this case study, we have adopted a simple approach to generating future climate change scenarios. Rather than compounding the modelling uncertainty through additional steps (for instance, downscaling of GCM results and/or use of a stochastic weather generator), we have simply taken the daily weather observation data for the site and perturbed each value according to the regional seasonal projected changes from CSIRO (2007) for the low emissions marker scenario (B1) and high emissions marker scenario (A1FI). All perturbed values are for a 20-year period centred around 2070, relative to the baseline period of 1980-1999. Perturbations 
Table 3. Changes to rainfall and Potential Evaporation for the Fleurieu Peninsula region (from CSIRO, 2007).

\begin{tabular}{|c|c|c|c|c|c|c|c|c|}
\hline \multirow[b]{3}{*}{ Percentile } & \multicolumn{8}{|c|}{ Rainfall: \% change -2070 relative to $1980-1999$} \\
\hline & \multicolumn{4}{|c|}{ low emissions } & \multicolumn{4}{|c|}{ high emissions } \\
\hline & Summer & Autumn & Winter & Spring & Summer & Autumn & Winter & Spring \\
\hline 10 & -30 & -15 & -15 & -30 & -30 & -30 & -30 & -50 \\
\hline 50 & -3.5 & -3.5 & -7.5 & -15 & -7.5 & -7.5 & -15 & -30 \\
\hline \multirow[t]{3}{*}{90} & 15 & 15 & 0 & 0 & 30 & 15 & 3.5 & 3.5 \\
\hline & \multicolumn{8}{|c|}{ Potential Evaporation: \% change -2070 relative to $1980-1999$} \\
\hline & \multicolumn{4}{|c|}{ low emissions } & \multicolumn{4}{|c|}{ high emissions } \\
\hline Percentile & Summer & Autumn & Winter & Spring & Summer & Autumn & Winter & Spring \\
\hline 10 & 0 & 3 & 3 & 0 & 0 & 6 & 6 & 0 \\
\hline 50 & 3 & 6 & 10 & 3 & 6 & 10 & 14 & 6 \\
\hline 90 & 6 & 10 & 18 & 6 & 14 & 18 & 18 & 10 \\
\hline
\end{tabular}

Table 4. Modelled mass balances (average annual) under baseline and climate change scenarios.

\begin{tabular}{|c|c|c|c|c|c|c|c|c|}
\hline \multirow[b]{2}{*}{ Units } & \multirow[b]{2}{*}{ Variable } & \multirow[b]{2}{*}{ baseline } & \multicolumn{3}{|c|}{ Low emissions } & \multicolumn{3}{|c|}{ High emissions } \\
\hline & & & $\begin{array}{r}10 \text { th } \\
\text { percentile }\end{array}$ & $\begin{array}{r}50 \text { th } \\
\text { percentile }\end{array}$ & $\begin{array}{r}\text { 90th } \\
\text { percentile }\end{array}$ & $\begin{array}{r}10 \text { th } \\
\text { percentile }\end{array}$ & $\begin{array}{r}50 \text { th } \\
\text { percentile }\end{array}$ & $\begin{array}{r}\text { 90th } \\
\text { percentile }\end{array}$ \\
\hline $\mathrm{mm} \mathrm{ha}^{-1}$ & Rainfall & 801 & 642 & 737 & 839 & 523 & 672 & 869 \\
\hline $\mathrm{mm} \mathrm{ha}^{-1}$ & Evaporation & 504 & 450 & 502 & 546 & 415 & 484 & 565 \\
\hline $\mathrm{mm} \mathrm{ha}^{-1}$ & Runoff & 7.82 & 3.09 & 5.07 & 8.76 & 0.93 & 3.23 & 9.83 \\
\hline $\mathrm{mm} \mathrm{ha}^{-1}$ & Streamflow & 130 & 86 & 104 & 129 & 52 & 85 & 134 \\
\hline tons ha ${ }^{-1}$ & Salt & 0.30 & 0.23 & 0.26 & 0.29 & 0.18 & 0.23 & 0.30 \\
\hline
\end{tabular}

for rainfall and potential evaporation are shown in Table 3, where the GCM spread is shown by percentile rankings as in CSIRO (2007). For each emissions scenario, we use the 10th, 50th and 90th percentile changes to generate separate perturbed climate sequences for input to GWLF, so that the model covers the spread of GCM results and in turn produces upper, median and lower projections of runoff, streamflow and TDS. The process is illustrated schematically in Fig. 5.

We recognise that there are limits to such an approach but for the purpose of demonstrating the influence of emissions scenario on hydrological model outputs, this method is thought to produce a sufficiently plausible set of perturbed climate sequences to allow a meaningful comparison.

\subsection{Results}

A one year time-slice of the streamflow hydrograph is presented for the year 1999, for low emissions (Fig. 6) and high emissions (Fig. 7) to qualitatively illustrate the influence of the emissions scenario on GWLF model results. In the low emissions scenario, it can be seen that the predicted hydrograph for the median case represents only a modest change relative to the baseline. Model spread is large relative to the predicted change, with the upper bound indicating an increase in streamflow and the lower bound indicating a decrease of a similar magnitude. In the high emissions scenario, the upper case is almost identical to that for the low emissions scenario. However, both the median and lower cases are substantially lower, indicating a much larger spread of model results.

Table 4 shows the annual average value for a number of key model outputs over the 1980-1999 baseline period, as well as each perturbed climate change scenario. To compare the influence of the emissions scenario quantitatively, for each emissions scenario we define model spread $S$ as the difference between extreme model predictions (where the input climate sequence was perturbed by the 10th and 90th percentile GCM projections) divided by the median:

$S=\frac{\left|P_{10}-P_{90}\right|}{P_{50}}$

where $P_{n}$ is the predicted value of a variable of interest and the subscript $n$ represents the percentile ranking of the scenario. We also define a proportional change $C_{50}$ as the 
Table 5. Model spread and proportional change.

\begin{tabular}{lrrrrr}
\hline & \multicolumn{2}{c}{ Model Spread $(S)$} & & \multicolumn{2}{c}{ Proportional Change $\left(C_{50}\right)$} \\
\cline { 2 - 3 } \cline { 5 - 6 } & $\begin{array}{r}\text { low } \\
\text { emissions }\end{array}$ & $\begin{array}{c}\text { high } \\
\text { emissions }\end{array}$ & & $\begin{array}{c}\text { low } \\
\text { emissions }\end{array}$ & $\begin{array}{r}\text { high } \\
\text { emissions }\end{array}$ \\
\hline Rain & $27 \%$ & $51 \%$ & & $-8 \%$ & $-16 \%$ \\
Evaporation & $19 \%$ & $31 \%$ & & $-1 \%$ & $-4 \%$ \\
Runoff & $112 \%$ & $275 \%$ & & $-35 \%$ & $-59 \%$ \\
Streamflow & $41 \%$ & $97 \%$ & & $-20 \%$ & $-35 \%$ \\
TDS & $25 \%$ & $54 \%$ & & $-13 \%$ & $-23 \%$ \\
\hline
\end{tabular}

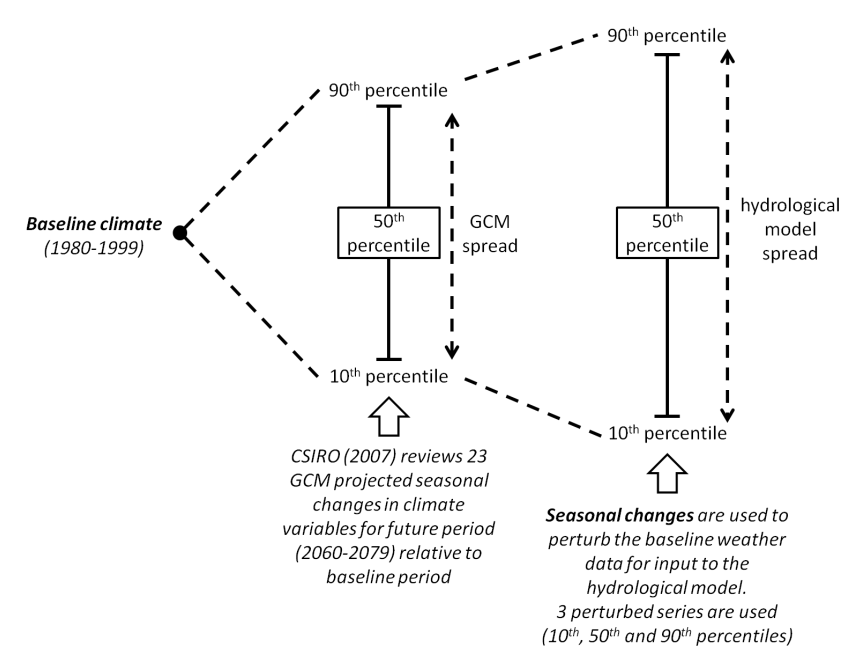

Fig. 5. Schematic showing climate scenario development and treatment of model spread.

difference between the median prediction and the baseline value, divided by the baseline value:

$C_{50}=\frac{P_{50}-P_{\text {baseline }}}{P_{\text {baseline }}}$

$S$ and $C_{50}$ are evaluated for each model output (from Table 4), and the results are shown in Table 5.

By quantifying both the proportional change $\left(C_{50}\right)$ and the model spread $(S)$ in mean projections, we see that both parameters are substantially influenced by the emissions scenario. Under a high emissions scenario, $C_{50}$ is $60-100 \%$ greater than under a low emissions scenario. Although $S$ is large in both the low and high emissions scenarios, it is important to observe that in all parameters except evaporation, $S$ is at least $100 \%$ greater in the high emissions case than in the low emissions scenario (and in the case of evaporation, $S$ is $70 \%$ greater under high emissions than low emissions). This suggests that if the A1FI scenario was eliminated on the basis of fossil fuel resource limits, and instead only the B1 scenario was considered as suggested by published studies on fossil fuel constraints, a significant reduction would re-

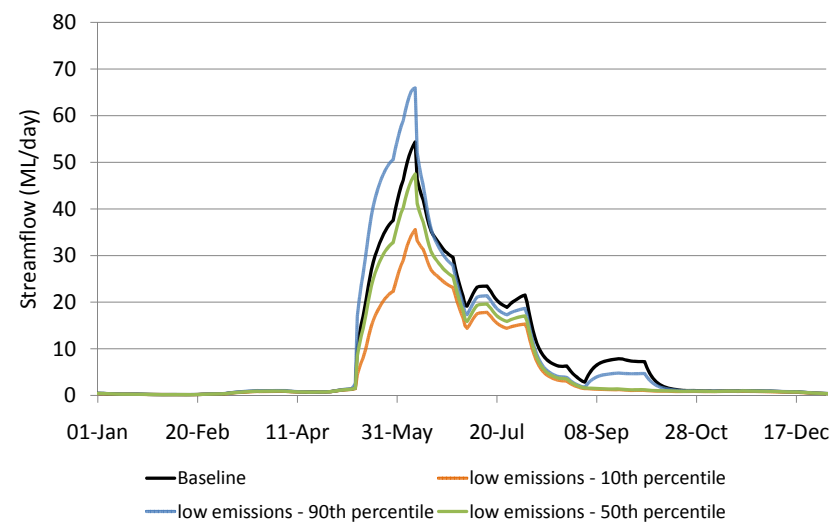

Fig. 6. One year time-slice (1999) of the hydrograph for baseline and low emissions scenario.

sult in (a) the magnitude of the projected change and (b) the uncertainty surrounding that projection.

We have analysed the temporal distribution of modeled streamflow in order to determine the projected changes in median, dry and wet years and thereby characterise - albeit simplistically - extreme events. To do this, the GWLF results are analysed under baseline and perturbed conditions and the 10th, 50th and 90th percentiles are determined for the annual streamflow (in ML yr ${ }^{-1}$, for each calendar year). The results are shown in Fig. 8. The left-hand set of columns represents the simulated baseline conditions (i.e. no climate change). In this case, the driest $10 \%$ of years have streamflow dropping below about $1500 \mathrm{ML}$, and the wettest $10 \%$ has flows of slightly over $5000 \mathrm{ML} \mathrm{yr}^{-1}$. Moving to the low emissions scenario (middle set of columns), we observe a modest reduction in 10th, 50th and 90th percentile flows. Note that the columns are the GWLF results using the median projected climate change (i.e. the mid-range GCM outputs), whereas the error bars reflect the GWLF model spread resulting from the 10th and 90th percentile climate scenarios (see Fig. 5). This suggests that under low emissions, the uncertainty attached to the change in streamflow is of a similar order to the level of change itself. When we consider the high emissions case (right-hand set of columns), the results 


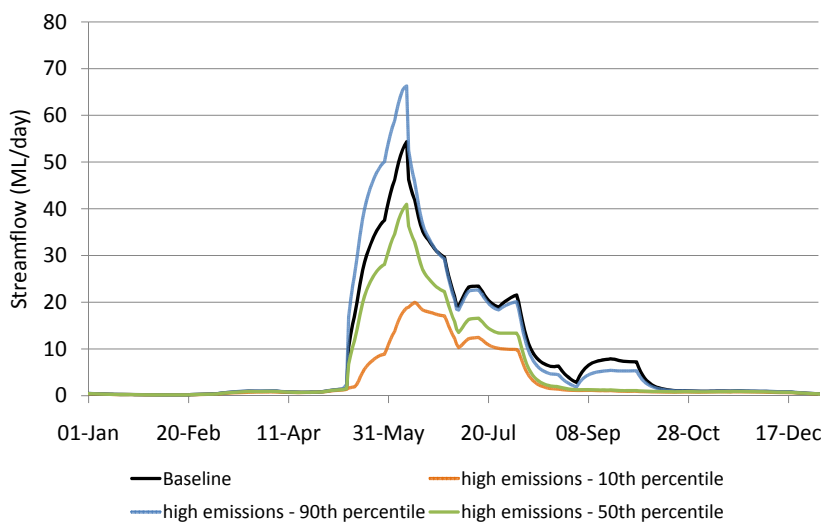

Fig. 7. One year time-slice (1999) of the hydrograph for baseline and high emissions scenario.

are quite striking. Here we see a continuation of the downwards trend in median projections for streamflow (drier conditions than those projected under low emissions), but now the error bars indicate great uncertainty from the range of climate projections used as input to the GWLF model.

What we see in Fig. 8 is that even in our simple catchment model, under a high emissions scenario, extreme (modelled) situations can theoretically arise. In this case the confluence of a significant increase in evaporation and a significant decrease in precipitation yields an extreme-model scenario in which the streamflow apparently drops to nearly zero in the driest $10 \%$ of years. This would typically be interpreted as "a potential increase in extreme events". On the other hand, under the low emissions scenario, while the projected trend in streamflow is still downward, the worst-case modelled results are far less extreme, and the stream does still flow substantially during dry years. It must be remembered that this is a deliberately simple hydrological model with a basic approach to climate change scenarios. However, we believe the results are useful and informative, especially if it is accepted that the high emissions case can be discounted.

\section{Sustainability issues beyond climate change}

In some studies, it has been the non-climatic aspects of the future scenario, such as the assumptions of regional population growth, that dominate the result, rather than the climate change itself. For instance, Arnell (2004) investigated water scarcity under SRES scenarios and noted that regional water scarcity was intimately linked to population, and that population growth projections varied significantly between scenarios. Vörösmarty et al. (2000) had previously reported similar results over a shorter timeframe (to 2025), where global population growth dominated the water scarcity problem.

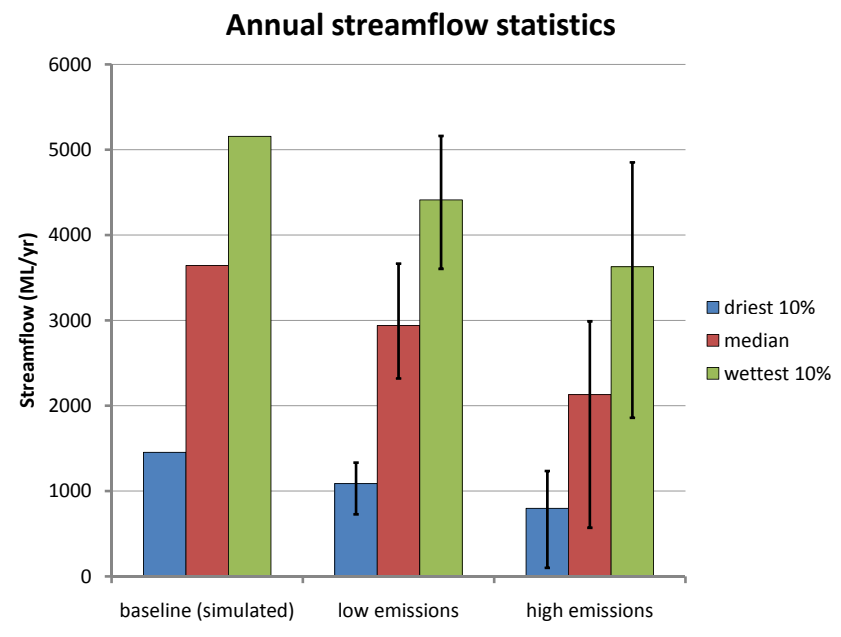

Fig. 8. Simulated streamflow $\left(\mathrm{ML} \mathrm{yr}^{-1}\right)$ in dry years (10th percentile), median years and wet years (90th percentile), for baseline, low emissions and high emissions scenarios. Coloured bars indicate GWLF model results using median climate model parameters; error bars indicate spread in GWLF model results from using upper and lower climate model projections.

Koutsoyiannis et al. (2009a) described the chaos and uncertainty (internal variability) inherent in rainfall patterns and compared this to the rather more certain projections of population growth and energy shortages. They suggested that planners should at least give increased consideration to environmental, social and economic changes other than to climate change alone. This supports a similar conclusion of $\mathrm{Nel}$ and Cooper (2009), who proposed that energy shortages will present a much greater problem than climate change. If the conventional projections of high fossil fuel growth prove impossible, then there are profound implications for communities. Apart from the significance this has for climate change uncertainty, energy is crucial to the global economy and human wellbeing, and lower-than-projected energy availability suggests real limits to the global economy. Nel and van Zyl (2010) presented a new economic model that accounted for energy resource constraints, projecting a reduction in global GDP in the second half of the 21st century. Hamilton (2009) contended that the 2008 Global Financial Crisis was itself triggered by high oil prices. These factors, coupled with the relative certainty of ongoing global population growth, point to severe problems outside of climate change.

\section{Conclusions and recommendations}

Emissions scenarios are a significant factor for long-term projections of water resources and reducing the spread of emissions scenarios would help to reduce overall uncertainty in climate projections. A body of literature is emerging that points to a peak and decline in global fossil fuel production occurring sometime in the 21 st century and this provides 
an opportunity to refine emissions forecasts. In particular, there is evidence of a very significant overestimate of coal resources and possible future coal production levels at the time of the IPCC's SRES. It appears that the current upper emissions scenarios can probably be rejected, and the medium scenarios may also be unrealistic, leaving the low and lowmedium scenarios as the most likely future for planning purposes. Specifically, recently published fossil fuel trajectories appear to be consistent with either the B1 or A1T marker scenarios from SRES, or the low-medium RCP 4.5 scenario from the new RCP series soon to be adopted in the IPCC's Fifth Assessment Report (AR5). A simple case study has shown that limiting projections to the low emissions (B1) scenario can result in a reduction in uncertainty for changes to hydrological variables such as rainfall, temperature and potential evaporation.

There is still considerable uncertainty as to whether a low emissions trajectory (due to either climate change policy or due to reaching natural fossil fuel limits) could still be sufficient to trigger significant climate change. Improved dialogue is needed between climate modelers, fossil fuel forecasters and policy-makers. In particular, as the world seeks to augment declining conventional energy sources with unconventional supplies (such as shale gas), the proportion of fugitive emissions is set to rise; furthermore, as methane is a far more potent greenhouse gas than carbon dioxide (despite being shorter-lived in the atmosphere), these extra fugitive emissions should be considered explicitly in emissions scenarios. We therefore recommend future research into rising proportions of non- $\mathrm{CO}_{2}$ emissions that may result from unconventional fossil fuel sources.

Physical climate variables, such as emissions, temperature and rainfall, and socio-economic variables, such as population, GDP and human wellbeing, all need to be addressed in light of projected limits to fossil fuel energy production. In addition, these should all be incorporated into revised socio-economic scenarios. Existing climate change projections should be revisited on a case-by-case basis, to ascertain whether particular impact or adaptation studies need to be re-run with lower emissions scenarios.

For climatic and hydrological modelers with an interest in generating realistic scenarios for adaptation purposes, there may be merit in a shift in focus away from the debate around increasingly uncertain impacts from the highest emissions trajectories, and more towards the development of improved regional models, to understand in more detail the most likely impacts from a lower degree of global warming. If the severity and uncertainty surrounding emissions scenarios can indeed be reduced, then a sound approach to long-term hydrological planning may involve a stochastic framework based on the statistical interpretation of historical data, with any deterministic modelling of future climate change to be carried out within the stochastic framework as recommended by Koutsoyiannis (2010). In addition, for water resources planning, it would be prudent to consider climate change impacts as a potential source, but not the only source, of vulnerability over the next 100 years. The biggest threat to the world's freshwater supplies may not be from climate change at all, but rather from a chronic shortage of energy for pumping and treating water, as well as for building and maintaining crucial storage and distribution infrastructure.

Acknowledgements. The authors thank Demetris Koutsoyiannis, Mohammad Kamruzzaman, Rezaul Chowdhury, Richard Mackey, Ugo Bardi, Mikael Höök, Antonis Christofides and one anonymous referee for constructive comments throughout the review process, and thank Peter Kretschmer for his background work on the Scott Creek case study.

Edited by: D. Koutsoyiannis

\section{References}

Aleklett, K., Höök, M., Jakobsson, K., Lardelli, M., Snowden, S., and Söderbergh, B.: The Peak of the Oil Age - Analyzing the world oil production Reference Scenario in World Energy Outlook 2008, Energy Policy 38, 1398-1414, 2010.

Allen, D. M., Mackie, D. C., and Wei, M.: Groundwater and climate change: a sensitivity analysis for the Grand Forks aquifer, southern British Columbia, Canada, Hydrogeol. J., 12, 270-290, 2003.

Allen, M. R., Frame, D. J., Huntingford, C., Jones, C. D., Lowe, J. A., Meinhausen, M., and Meinhausen, N.: Warming caused by cumulative carbon emissions towards the trillionth tonne, Nature, 458 (April 2009), 1163-1166, 2009.

Anagnostopoulos, G. G., Koutsoyiannis, D., Christofides, A., Efstratiadis, A., and Mamassis, N.: A comparison of local and aggregated climate model outputs with observed data, Hydrol. Sci. J., 55(7), 1094-1110, 2010.

Arnell, N. W.: Effects of IPCC SRES* emissions scenarios on river runoff: a global perspective, Hydrol. Earth Syst. Sci., 7, 619641, doi:10.5194/hess-7-619-2003, 2003.

Arnell, N.: Climate change and global water resources: SRES scenarios and socio-economic scenarios, Global Environ. Change, 14, 31-52, 2004.

Banks, E. W., Simmons, C. T., Love, A. L., Cranswick, R., Werner, A. D., Bestland, E. A., Wood, M., Wilson, T.: Fractured bedrock and saprolite hydrogeologic controls on groundwater/surfacewater interaction: a conceptual model (Australia), Hydrogeol. J., 17(8), 1969-1989, 2009.

Bartlett, A. A.: Forgotten fundamentals of the energy crisis, American Journal of Physics 46 (Sept 1978), 876-888, 1978.

Bartlett, A. A.: Correction to Estimates of Fossil Fuel Lifetimes, J. Chemical Education, 58(6), 501-502, 1981.

Bartlett, A. A.: Expert predictions of the lifetimes of non-renewable resources, The Mathematical Gazette 78(482), 127-129, 1994.

Bartlett, A. A.: An Analysis of U.S. and World Oil Production Patterns Using Hubbert-Style Curves, Mathematical Geology, 32(1), 1-17, 2000.

Bentley, R. W.: Global oil \& gas depletion: an overview, Energy Policy, 30, 189-205, 2002.

Betts, R. A., Boucher, O., Collins, M., Cox, P. M., Falloon, P. D., Gedney, N., Hemming, D. L., Huntingford, C., Jones, C. D., Sexton, D. M. H., and Webb, M. J.: Projected increase in continental 
runoff due to plant responses to increasing carbon dioxide, Nature, 448 (August 2007), 1037-1042, 2007.

Booij, M. J.: Impact of climate change on river flooding assessed with different spatial model resolutions, J. Hydrol., 303, 176198, 2005.

Brecha, R. J.: Emission scenarios in the face of fossil-fuel peaking, Energy Policy, 36, 3492-3504, 2008.

Christofides, A. and Koutsoyiannis, D.: Causality in climate and hydrology, Presentation given at the European Geosciences Union General Assembly, Vienna, 5 April 2011.

Covey, C., Achuta Rao, K. M., Cubasch, U., Jones, P., Lambert, S. J., Mann, M. E., Phillips, T. J., and Taylor, K. E.: An overview of results from the Coupled Model Intercomparison Project, Global Planet. Change, 37, 103-133, 2003.

CSIRO: Climate Change in Australia, Technical Report, Available online: www.climatechangeinaustralia.com.au, 2007.

Döll, P.: Impact of climate change and variability on irrigation requirements: a global perspective, Climatic Change, 54, 269-293, 2002.

Doose, P.: Projections of fossil fuel use and future atmospheric $\mathrm{CO}_{2}$ concentrations, The Geochemical Society Special Publications, 9, 187-195, 2004.

Douville, H., Chauvin, F., Planton, S., Royer, J. F., Salas-Melia, D., and Tyteca, S.: Sensitivity of the hydrological cycle to increasing amounts of greenhouse gases and aerosols, Clim. Dynam., 20, 45-68, 2002.

Downing, T. E., Butterfield, R. E., Edmonds, B., Knox, J. W., Moss, S., Piper, B. S., Weatherhead, E. K., and the CCDeW project team: Climate change and the demand for water, Research Report, Stockholm Environment Institute, Oxford Office, Oxford, 2003.

Frank, D. C., Esper, J., Raible, C. C., Büntgen, U., Trouet, V., Stocker, B., and Joos, F.: Ensemble reconstruction constraints on the global carbon cycle sensitivity to climate, Nature, 463, January 2010

Friedlingstein, P., Cox, P., Betts, R., Bopp, L., von Bloh, W., Brovkin, V., Cadule, P., Doney, S., Eby, M., Fung, I., Bala, G., John, J., Jones, C., Joos, F., Kato, T., Kawamiya, M., Knorr, W., Lindsay, K., Matthews, H.D., Raddatz, T., Rayner, P., Reick, C., Roeckner, E., Schnitzler, K.-G., Schnur, R., Strassman, K., Weaver, A. J., Yoskikawa, C., and Zeng, N.: Climate-Carbon Cycle Feedback Analysis: Results from the $\mathrm{C}^{4}$ MIP Model Intercomparison, J. Climate, 19, 3337-3353, 2006

Garen, D. C. and Moore, D. S.: Curve number hydrology in water quality modeling: Uses, abuses, and future directions, J. Am. Water Resour. As., 41(2), 377-388, 2005.

Haith, D. A., Mandel, R., and Wu, R. S.: Generalized Watershed Loading Functions Version 2.0 User's Manual, Cornell University, Ithaca, New York, 1992.

Hamilton, J. D.: Causes and Consequences of the Oil Shock of 2007-08, in: Romer and Wolfers (Eds.), Brookings Papers on Economic Activity, Spring 2009 Conference, 215-284, Brookings Institution Press 2009.

Harrington, G.: Hydrological Investigation of the Mount Lofty Ranges, Progress Report 4: Groundwater - surface water interactions in the Scott Creek, Marne River and Tookayerta Creek Catchments. DWLBC 2004/11, Dept of Water, Land and Biodiversity Conservation, 2004.

Hawkins, E. and Sutton, R.: The potential to narrow uncertainty in regional climate predictions, B. Am. Meteorol. Soc., 90 (August 2009), 1095-1107, 2009.

Hawkins, E. and Sutton, R.: The potential to narrow uncertainty in regional precipitation change, Clim. Dynam., doi:10.1007/s00382-010-0810-6, 2011.

Höök, M., Sivertsson, A., and Aleklett, K.: Validity of the Fossil Fuel Production Outlooks in the IPCC Emission Scenarios, Nat. Resour. Res., 19(2), 63-81, 2010a.

Höök, M., Zittel, W., Schindler, J., and Aleklett, K.: Global coal production outlooks based on a logistic model, Fuel, 89(11), 3546-3558, 2010b.

Hubbert, M. K.: Energy from Fossil Fuels, Science, 109, February 1949, 103-109, 1949.

Hubbert, M. K.: Nuclear Energy and the Fossil Fuels, presentation to the Spring Meeting of the Southern District Division of Production, American Petroleum Institute, Texas, March 7-9, 1956.

James-Smith, J. and Harrington, G.: Hydrological Investigation of the Mount Lofty Ranges, Progress Report 1: hydrogeology and drilling phase 1 for Scott Creek Catchment, Dept of Water, Land, and Biodiversity Conservation, 2002.

Jones, C. D., Cox, P. M., and Huntingford, C.: Climate-carbon cycle feedbacks under stabilization: uncertainty and observational constraints, Tellus 58B(5), 603-613, 2006.

Jones, R. N.: An Environmental Risk Assessment/Management Framework for Climate Change Impact Assessments, Nat. Hazards, 23(2), 197-230, 2001.

Kharecha, P. A. and Hansen, J. E.: Implications of "peak oil" for atmospheric $\mathrm{CO}_{2}$ and climate, Global Biogeochem. Cy., 22, GB3012, doi:10.1029/2007GB003142, 2008.

Kirono, D. G. C., Kent, D. M., Hennessy, K. J., and Mpelasoka, F.: Characteristics of Australian droughts under enhanced greenhouse conditions: Results from 14 global climate models, J. Arid Environ., 75, 566-575, 2011.

Koutsoyiannis, D.: HESS Opinions "A random walk on water", Hydrol. Earth Syst. Sci., 14, 585-601, doi:10.5194/hess-14-5852010, 2010.

Koutsoyiannis, D., Makropoulos, C., Langousis, A., Baki, S., Efstratiadis, A., Christofides, A., Karavokiros, G., and Mamassis, N.: HESS Opinions: "Climate, hydrology, energy, water: recognizing uncertainty and seeking sustainabilit", Hydrol. Earth Syst. Sci., 13, 247-257, doi:10.5194/hess-13-247-2009, 2009a.

Koutsoyiannis, D., Montanari, A., Lins, H. F., and Cohn, T. A. Climate, hydrology and freshwater: towards an interactive incorporation of hydrological experience into climate research DISCUSSION of "The implications of projected climate change for freshwater resources and their management", Hydrolog. Sci J., 54(2), 394-405, 2009b.

Knutti, R.: The end of model democracy?, An editorial comment, Climatic Change, 102, 395-404, 2010.

Kundzewicz, Z. W., Mata, L. J., Arnell, N. W., Döll, P., Kabat, P., Jiménez, B., Miller, K. A., Oki, T., Sen, Z., and Shiklomanov, I. A.: Freshwater resources and their management. Climate Change 2007: Impacts, Adaptation and Vulnerability. Contribution of Working Group II to the Fourth Assessment Report of the Intergovernmental Panel on Climate Change, edited by: Parry, M. L., Canziani, O. F., Palutikof, J. P., van der Linden, P. J., and Hanson, C. E., Cambridge University Press, Cambridge, UK, 173-210, 2007.

Kundzewicz, Z. W., Mata, L. J., Arnell, N. W., Döll, P., Jimenez, B., 
Miller, K., Oki, T., and Sen, Z.: Water and climate projections, Hydrolog. Sci. J., 54(2), 406-415, 2009.

Kundzewicz, Z. W. and Stakhiv, E. Z.: Are climate models "ready for prime time" in water resources management applications, or is more research needed? Editorial, Hydrolog. Sci. J., 55(7), 1085-1089, 2010.

Kwantes, E.: Characterising the hydraulic properties of a weathered fractured rock aquifer in the Scott Creek Catchment in South Australia. Masters Thesis, Flinders University, Adelaide, 2006.

Laherrere, J.: Estimates of Oil Reserves, Paper presented at the EMF/IEA/IEW meeting IIASA, Lazenburg, Austria, June 19, 2001.

Lee, K. Y., Fisher, T. R., Jordan, T. E., Correll, D. L., and Weller, D. E.: Modeling the hydrochemistry of the Choptank River Basin using GWLF and Arc/Info: 1. Model calibration and validation. Biogeochemistry, 49(2), 143-173, 2000.

Lee, K. Y., Fisher, T. R., and Rochelle-Newall, E.: Modeling the hydrochemistry of the choptank river basin using GWLF and Arc/Info: 2. Model validation and application, Biogeochemistry, 56(3), 311-348, 2001.

Leggett, J., Pepper, W. J., and Swart, R. J.: Emissions scenarios for IPCC: An update. In Climate Change 1992. Supplementary Report to the IPCC Scientific Assessment, edited by: Houghton, J. T., Callander, B. A., and Varney, S. K., Cambridge University Press, Cambridge, 69-95, 1992.

Lin, B. and Liu, J.: Estimating coal production peak and trends of coal imports in China, Energy Policy, 38, 512-519, 2010.

Lloyd, B. and Subbarao, S.: Development challenges under the Clean Development Mechanism (CDM) - Can renewable energy initiatives be put in place before peak oil?, Energy Policy, 37, 237-245, 2009.

Mahecha, M. D., Reichstein, M., Carvalhais, N., Lasslop, G., Lange, H., Seneviratne, S. I., Vargas, R., Ammann, C., Arain, M. A., Cescatti, A., Janssens, I. A., Migliavacca, M., Montagnani, L., and Richardson, A. D.: Global Convergence in the Temperature Sensitivity of Respiration at Ecosystem Level, Science 329, August 2010.

Manning, M. R., Edmonds, J., Emori, S., Grubler, A., Hibbard, K., Joos, F., Kainuma, M., Keeling, R.F., Kram, T., Manning, A. C., Meinhausen, M., Moss, R., Nakicenovic, N., Riahi, K., Rose, S. K., Smith, S., Swart, R., and van Vuuren, D. P.: Misrepresentation of the IPCC $\mathrm{CO}_{2}$ emission scenarios, Nature Geoscience 3 (June 2010), 376-377, 2010.

Meadows, D. H., Meadows, D. L., Randers, J., and Berens, W. W.: The Limits to Growth: A report for the Club of Rome's project on the predicament for mankind, Universe Books, New York USA, 205 pp., 1972.

Meinhausen, M., Meinhausen, N., Hare, W., Raper, S. C. B., Frieler, K., Knutti, R., Frame, D. J., and Allen, M. R.: Greenhouse-gas emission targets for limiting global warming to $2^{\circ} \mathrm{C}$, Nature 458 (April 2009), 1158-1163, 2009.

Mishra, S. K. and Singh, V.: Soil Conservation Service Curve Number (SCS-CN) Methodology. Kluwer Academic Publishers, Dordrecht, Netherlands, 513 pp., 2003.

Mohr, S.: Projection of world fossil fuel production with supply and demand interactions, Ph.D. Thesis, The University of Newcastle, Australia, 2010.

Mohr, S. H. and Evans, G. M.: Peak Oil: Testing Hubbert's Curve via Theoretical Modeling, Nat. Resour. Res., 17(1), 1-11, 2008.
Mohr, S. H. and Evans, G. M.: Forecasting coal production until 2100, Fuel 88, 2059-2067, 2009.

Mohr, S. H. and Evans, G. M.: Long term prediction of unconventional oil production, Energy Policy, 38, 265-276, 2010.

Morton, F. I.: Operational estimates of areal evapotranspiration and their significance to the science and practice of hydrology, J. Hydrol. 66, 1-76, 1983.

Moss, R. H., Edmonds, J. A., Hibbard, K. A., Manning, M. R., Rose, S. K., van Vuuren, D. P., Carter, T. R., Emori, S., Kainuma, M., Kram, T., Meehl, G. A., Mitchell, J. F. B., Nakicenovic, N., Riahi, K., Smith, S. J., Stouffer, R. J., Thomson, A. M., Weyant, J. P., and Wilbanks, T. J.: The next generation of scenarios for climate change research and assessment, Nature, 463, (Feb 2010), 747-756, 2010.

Murray, J. W.: Peak Oil and Climate Change, presentation to AGU Joint Assembly, Toronto, 26 May 2009.

Myhre, G., Alterskjaer, K., and Lowe, D.: A fast method for updating global fossil fuel carbon dioxide emissions, Environm. Res. Lett., 4(3) 034012, doi:10.1088/1748-9326/4/3/034012, 2009.

Nakicenovic, N. and Swart, R. (Eds.): Special Report on Emissions Scenarios: A Special Report of Working Group III of the Intergovernmental Panel on Climate Change. Cambridge University Press, Cambridge, New York, 570 pp., 2000.

Nel, W. P. and Cooper, C. J.: Implications of fossil fuel constraints on economic growth and global warming, Energy Policy, 37, 166-180, 2009.

Nel, W. P. and van Zyl, G.: Defining limits: energy constrained economic growth, Applied Energy, 87, 168-177, 2010.

Patzek, T. W. and Croft, G. D.: A global coal production forecast with multi-Hubbert cycle analysis, Energy, 35, 3109-3122, 2010.

Rutledge, D.: Estimating long-term world coal production with logit and probit transforms, Int. Jo. Coal Geol., 85, 23-33, 2011.

Schneiderman, E. M., Pierson, D. C., Lounsbury, D. G., and Zion, M. S.: Modeling the hydrochemistry of the Cannonsville watershed with Generalized Watershed Loading Functions (GWLF), J. Am. Water Resour. As., 38(5), 1323-1347, 2002.

Siegenthaler, U. and Joos, F.: Use of a simple model for studying oceanic tracer distributions and the global carbon cycle, Tellus, 44B, 186-207, 1992.

Sivakumar, B. and Sharma, A.: Climate change impacts on water resources planning and management: scientific challenges and beyond, $18^{\text {th }}$ World IMACS / MODSIM Congress, Cairns, Australia 13-17 July 2009, http://mssanz.org.au/modsim09, 2009.

Smith, I. and Chandler, E.: Refining rainfall projections for the Murray Darling Basin of south-east Australia - the effect of sampling model results based on performance, Climatic Change, 102, 377-393, 2010.

Sorrell, S., Miller, J., Bentley, R., and Speirs, J.: Oil futures: A comparison of global supply forecasts, Energy Policy, 38(9),4990 5003, 2010a.

Sorrell, S., Speirs, J., Bentley, R., Brandt, A., and Miller, R.: Global oil depletion: A review of the evidence, Energy Policy, 38(9), 5290-5295, 2010b.

Tans, P.: An accounting of the observed increase in oceanic and atmospheric $\mathrm{CO}_{2}$ and an outlook for the future, Oceanography, 22(4), 26-35, 2009.

Vörösmarty, C. J., Green, P., Salisbury, J., and Lammers, R. B.: Global Water Resources: Vulnerability from Climate Change and Population Growth, Science, 289(5477), 284-288, 2000. 
Ward, J. D. and Nel, W. P.: Comment on Fossil-fuel constraints on global warming by A. Zecca and L. Chiari [Energy Policy 38 (2010) 1-3], Energy Policy, doi:10.1016/j.enpol.2010.01.026, in press, 2010.

WEC: Survey of Energy Resources, published by the World Energy Council, London, 1998.
WEC: Survey of Energy Resources, published by the World Energy Council, London, 2007.

Werner, A. D., Wood, M., Simmons, C. T., and Lockington, D. A.: Salinograph trends as indicators of the recession characteristics of stream components, Hydrol. Process., 22, 3020-3028, 2008.

Wilby, R. L.: Evaluating climate model outputs for hydrological applications, Hydrolog. Sci. J., 55(7), 1090-1093, 2010. 